\title{
El uso de fuentes literarias e historias de vida como recursos para la investigación social cualitativa Una lectura microsociológica de La vida de Laza- rillo de Tormes
}

\author{
Javier Andrés Piñeiro ${ }^{1}$ \\ javaeiro@hotmail.com \\ Rec. 15/12/2018, Apr. 02/04/2018
}

\section{Resumen:}

El presente artículo se propone trabajar el cruce entre literatura y ciencias sociales desde una perspectiva epistemológico-metodológica. Nuestra exposición tiene por principal objetivo destacar el valor que reviste para la investigación social cualitativa el recurso a historias de vida y obras literarias realistas (o costumbristas) como fuentes documentales a partir de las cuales es posible hacer una reconstrucción de los imaginarios, de la cultura, y de las características del orden social y de la vida cotidiana de una época y de un lugar. Para ello, realizaremos una lectura crítica de fragmentos escogidos de un producto cultural -la obra literaria La vida de Lazarillo de Tormes- a partir de supuestos, categorías y procedimientos prototípicos que pone en juego la teoría social que prioriza la perspectiva del sujeto. Por medio del análisis propuesto pretendemos entrar en el mundo de la vida cotidiana de los sectores sociales marginales de la Espańa del siglo XVI, y señalar cómo a partir de las prácticas cotidianas de personajes histórica y socialmente situados se hace posible revelar algunas características distintivas del orden social vigente.

Palabras clave: Literatura y Ciencias Sociales - Metodología y Teoría social cualitativa - Análisis documental de historias de vida y fuentes literarias - Sociología de la vida cotidiana - Hermenéutica.

\section{Abstract:}

The present article intends to adress the crossing between literature and social sciences from an epistemological-methodological perspective. Our 
main objective is to highlight the value for qualitative social research of the use of life stories and realistic literary works (or of local customs and manners) as documentary sources from which it is possible to reconstruct the imaginaries, the culture, and the characteristics of the social order and the daily life of a period and a place. For this, we will make a critical reading of selected fragments of a cultural product -the literary work $L a$ vida de Lazarillo de Tormes- based on assumptions, categories and prototypical procedures that bring into play the social theory that prioritizes the perspective of the subject. Through the proposed analysis we intend to enter the world of everyday life of the marginal social sectors of sixteenth-century Spain and point out how from the daily practices of historically and socially situated characters it is possible to reveal some distinguishing features of the current social order.

Keywords: Literature and Social Sciences - Methodology and Qualitative Social Theory - Documentary analysis of life stories and literary sources Sociology of daily life - Hermeneutics.

Para ser un verdadero novelista es necesario haber explorado toda la vida social, ya que la novela es la historia privada de las naciones.

Balzac, Pequeñas miserias de la vida conyugal

\section{Introducción}

Las estrategias metodológicas (y las técnicas que estas suponen) no son un apéndice o un mero agregado en una investigación, sino que dependen siempre muy fuertemente de los supuestos epistemológicos y teóricos de los que la investigación parta. Así como el cuestionario cerrado o el sondeo son estrategias hacia las que se orientan las epistemologías sociales que priorizan la búsqueda de lo cuantitativo, las epistemologías que ponen el foco en el sujeto como un ser simbólico y autorreflexivo no se volcarán tanto a la búsqueda del dato sino más bien a los procesos significantes, a la reconstrucción del sentido que los sujetos les otorgan a sus prácticas, al análisis de los productos culturales, en una palabra: a lo cualitativo. Es por esto que un abordaje epistemológico micro va de la mano con estrategias metodológicas cualitativas.

Entre las estrategias que pone en práctica la investigación social cualitativa para producir información respecto de sus objetos, el análisis (lingüístico, semiológico, histórico, sociológico, hermenéutico, etc.) de productos culturales de todo tipo juega un rol destacado, en tanto parte del supuesto de que si algo puede considerarse como un producto social es porque ese algo remite inexorablemente a procesos sociales. Si no hay producto sin producción, el análisis de un objeto cultural debe permitir la reconstrucción del complejo entramado social que le dio lugar y dentro del cual obtiene sentido en tanto que objeto. Ir de productos a procesos, de objetos culturales a conglomerados sociales significativos dentro de los cuales esos objetos valen como tales, es una de las marcas más distintivas que tiene un abordaje teórico microsocial. 
En el presente trabajo nos proponemos realizar una lectura crítica de fragmentos escogidos de un producto cultural -la obra literaria La vida de Lazarillo de Tormes-a partir de supuestos, categorías y procedimientos prototípicos que a la hora de llevar adelante una investigación pone en juego la teoría social que prioriza la perspectiva del sujeto. Por medio del análisis propuesto pretendemos entrar en el mundo de la vida cotidiana de los sectores sociales marginales de la España del siglo XVI, y señalar cómo a partir de las prácticas cotidianas de los actores se hace posible revelar algunas características distintivas del orden social vigente.

Consideramos no solamente legítimo sino también pertinente trabajar con una obra literaria de corte realista como fuente documental porque entendemos que a partir de su lectura es posible hacer una reconstrucción de los imaginarios sociales dentro de los cuales las prácticas de personajes histórica y socialmente situados adquieren un sentido peculiar y distintivo. María Luisa Lanzuela Corella señala, en este sentido, que:

La obra literaria no es un hecho aislado, es un reflejo, consciente o inconsciente, de la situación social, económica y política de un determinado momento histórico. El escritor no vive aislado sino integrado en una sociedad por un sinfín de nexos y relaciones. Además, no es sólo escritor, es otras muchas cosas; y su vida, como la de cualquier ser humano, se nutre del forcejeo entre la afirmación de su propia individualidad y las trabas que en los usos sociales encuentra para lograr esa individualidad. Por eso, la obra literaria está históricamente condicionada, en la medida en que toda sociedad es, por su misma esencia, histórica; y el componente socio-cultural actúa como ingrediente de la concepción artística. Giner de los Ríos llama la atención sobre el valor de la literatura como instrumento para averiguar la caracteriología de un pueblo, piensa: que el historiador puede y debe servirse de la producción literaria como de insuperable guía para explorar la recóndita intimidad de un momento histórico; la que no nos suele proporcionar la historia política. Según él, si la historia quiere descubrirnos el espíritu de los pueblos, tiene que buscar sus fuentes donde el espíritu se manifiesta de manera más libre e intensa; que, precisamente, no es en el terreno de lo socio-político, donde acostumbra, por cierto, a buscarlas; sino en una esfera más personal e íntima, la del arte, ya que la obra artística surge de lo más individual y característico que tiene el hombre; y dentro del arte, el historiador debe dirigirse muy especialmente a la literatura. La validez de la fuente literaria resulta innegable a la hora de analizar temas de historia social, detalles de la vida cotidiana o tendencias de mentalidades colectivas. (Lanzuela Corella, 2000, p. 259)

Lazarillo de Tormes es la historia de vida -un género siempre muy atractivo para la indagación microsociológica- de un lumpen español del siglo XVI, un relato autobiográfico cuya mirada está posada muy especialmente sobre el mundo de la vida cotidiana, ese mundo con el cual y en el cual los sujetos sociales interactúan a diario. El relato autobiográfico, que describe prácticas, usos y costumbres de la época, introduce la biografía en el mundo de la vida, permite acceder a lo macro a partir de lo micro. Es por este motivo que la escogimos y que Lazarillo de Tormes nos parece, por tanto, no sólo un producto sumamente apto para el análisis literario y la lectura hedonista, sino una obra de interés histórico y sociológico. 


\section{La novela realista y la historia de vida como fuentes para el análisis docu- mental sociológico e histórico}

La vida de Lazarillo de Tormes y de sus fortunas y adversidades es una novela española anónima, cuya primera edición conocida se remonta a 1554. Está escrita en primera persona y en estilo epistolar -a modo de carta dirigida a Vuestra Merced, el lector-, y en ella se cuenta de forma autobiográfica las vicisitudes que Lázaro de Tormes -huérfano de padre y entregado a los ocho años de edad por su madre, que no tiene los medios para mantenerlo, a un ciego que se lo pide como criado- experimenta a medida que va creciendo y sirviendo a diferentes amos (la mayoría de ellos religiosos de distinta jerarquía, cuyas costumbres y hábitos personales y sociales el relato satiriza muy fuertemente). ${ }^{1}$

Si bien Lázaro es un personaje ficticio, el relato de su historia de vida permite reconstruir las condiciones de vida reales, concretas, vividas, efectivamente experimentadas, de los sectores lúmpenes de la España del siglo XVI, al mismo tiempo que pone de manifiesto los usos y las costumbres del orden social de la sociedad de su tiempo. Desde una aproximación histórico-sociológica, el personaje de Lázaro -en el cual incluimos su forma de ver al mundo (y la manera en que esta va sufriendo modificaciones a lo largo del relato, desde su infancia como nińo inocente a su adultez como cínico consumado), los intercambios sociales en los que participa, las tácticas que emplea cotidianamente para sobrevivir en un medio que le es hostil- resulta profundamente significativo porque puede ser visto como sinécdoque de un mundo social significante, como parte -en tanto que niño abandonado a su suerte, en tanto que pobre, en tanto que mendigo, en tanto que criado, en tanto que lumpen- de un todo mayor: los desclasados, los marginales, los subalternizados de esa España que está asomando tímidamente la cabeza al mundo moderno. E incluso como sinécdoque de algo todavía mayor: la manera más o menos conflictiva en que estos sectores (el endogrupo de Lázaro) se vinculan con los dominantes (el exogrupo), en el contexto de un orden social legítimo. A diferencia de otras novelas de su época que relatan hazañas caballerescas, o ambientadas en contextos bucólicos o pastoriles, Lazarillo de Tormes es una verdadera epopeya del hambre, una mirada irónica y despiadada de la sociedad espańola del siglo XVI, de la que se muestran sus vicios y sus actitudes más hipócritas.

La vida de Lázaro de Tormes es, por consiguiente, una descripción más o menos fidedigna de su mundo cotidiano de todos los días, que es también el mundo cotidiano de aquellos con los que interactúa. El personaje pone en escena, sinecdóquicamente, las prácticas sociales (y los sentidos que los actores dan a las mismas) de un conjunto de seres subalternizados, conocedores de las deficiencias de su ser y de la importancia compensatoria que tiene el saber construirse una buena fachada.

Desde un punto de vista sociológico (e histórico) resulta de primordial interés todo aquello cuanto detalla la biografía novelada puesto que a partir de ella es posible hacer toda una reconstrucción de los imaginarios sociales de la época. Los imaginarios sociales estructuran comunidades de sentido, posibilitando que en el seno de una sociedad los sujetos que la conforman compartan cosmovisión, es decir, que tengan similares ideas y valores con respecto al mundo físico y social -considerado como un todo, y en las múltiples dimensiones que lo componen: normativas, éticas, políticas, filosóficas, religiosas, entre otras-, que tengan similares representaciones en torno a él, y que otorguen simila-

1 Esto motivó que Lazarillo de Tormes fuera una novela prohibida por la Inquisición, y que no volviera a publicarse íntegramente hasta el siglo XIX. 
res sentidos a las prácticas e intercambios materiales y simbólicos que, en tanto que seres comunitarios, llevan adelante con los individuos con que interactúan cotidianamente.

[...] una construcción cultural, histórica, comunicacional que opera en función de instituciones sociales y por actores sociales. El imaginario es un modo (cultural) de interpretar e interpelar al mundo. [...] El anclaje cultural e histórico del imaginario determina conductas sociales que funcionan positivamente en la sociedad.

[...] Hablar de imaginario es referirse a los sentidos presentes en un grupo social y que dan cuenta de la percepción del mundo social. Dicha percepción supone una organización imaginaria, que tiene una cierta función ordenadora de la relación entre los agentes sociales. Aquí entra en juego la concepción de la sociedad como interacción entre los individuos que la componen. En esa interacción el grupo social construye la representación, la imagen de sí misma. Se puede decir que el imaginario es el conjunto de imágenes, la representación hecha de memoria, experiencias y proyectos y/o utopias, de que se vale un grupo social para explicar, organizar, ordenar el mundo social, situarse y actuar en él. Es una construcción tanto consciente como inconsciente. (Martini y Halpern, 2000, pp. 72-73)

La idea de que un abordaje micro -como el que es posible hacer a partir del análisis de una historia de vida - es capaz de abrirnos la puerta al conocimiento de complejas realidades macro (como las que se ponen de manifiesto en los imaginarios sociales), está en la base de los desarrollos teóricos que traen a la escena sociológica la fenomenología, el interaccionismo simbólico y otras corrientes de corte hermenéutico a las cuales nos referiremos brevemente en el apartado que sigue a continuación.

\section{Sujeto, mundo de la vida, prácticas, símbolos y conocimiento de sentido común en la teoría social de Alfred Schütz y el interaccionismo simbólico}

El interaccionismo simbólico aborda la acción social desde la perspectiva de los participantes. Es por ello que se propone abordar el estudio de lo social no desde alguno de sus componentes estructurales, sino partiendo de la acción conjunta, vale decir, de la interacción social que se da en el encuentro y en las transacciones entre individuos ${ }^{2}$. Herbert Blumer, que fue quien acuño el término con el cual se conoce a la corriente y fue uno de sus principales impulsores teóricos, sostiene al respecto que:

Por lo que se refiere a la metodología y a la investigación, el estudio de la acción debería hacerse desde la posición del agente. Puesto que es este quien la confecciona basándose en lo que percibe, interpreta y enjuicia, habría que ver la situación operativa como la ve el actor, percibir los objetos como él los percibe, asumir su significado en función del que poseen para él, y seguir la línea de conducta del agente tal y como este la organiza. En suma, habría que asumir el papel del actor y contemplar su mundo desde su punto de vista. (Blumer, 1982, p. 54)

2 Mead vio a la sociedad humana como un proceso social diversificado en el que las personas se ven obligadas a crear acciones conjuntas para resolver las situaciones que afrontan. (Blumer, 1982, p. 53). 
Al afirmar que el sujeto posee un "sí mismo" -cuestión que ocupa un lugar principalísimo en la producción teórica de autores críticos del conductismo ortodoxo como George H. Mead-, el interaccionismo simbólico subraya fuertemente el decisivo carácter autorreflexivo que tienen las acciones humanas, el hecho de que el agente humano sea un objeto para sí mismo. La persona:

[...] puede percibirse, tener conceptos, actuar y comunicar consigo misma. De estos tipos de comportamiento se desprende que el individuo puede convertirse en el objeto de su propia acción, lo que le proporciona los medios de entablar una interacción consigo mismo (...). En suma, la posesión de un "sí mismo" dota al ser humano de un mecanismo de interacción consigo mismo que le permite afrontar el mundo, y que utiliza para conformar y orientar su propia conducta. El sí mismo es, por tanto, un permanente e incesante proceso reflexivo, y no una estructura: la percepción del propio yo nos coloca en posición de hacer algo con respecto al mismo, en lugar de limitarnos a darle expresión. [...] El proceso de la interacción consigo mismo no se limita a situar al ser humano en el mundo, sino que lo confronta con él; le exige hacerle frente y manipularlo mediante un proceso definitorio, en lugar de limitarse a responder, y le obliga no sólo a llevar a cabo su acción, sino a elaborarla. (Blumer, 1982, pp. 46-47)

En este "hacer su mundo", los humanos construyen un mundo de objetos en el que viven, y en relación con los cuales realizan sus actividades. Este mundo objetivo es, por tanto, un mundo de objetos socialmente construidos, no de meras entidades físicas. La naturaleza social de tales objetos los convierte en objetos significantes, o en objetos socialmente significativos. Los agentes interactúan respecto de estos objetos -cualquiera sea su condición, abstracta o concreta, real o imaginaria, natural o artificial, animada o inanimada-, en función del significado que estos tienen para ellos. Blumer sostiene al respecto que:

[...] desde el momento en que las personas se ven compelidas a actuar en función del significado de los objetos, el mundo de objetos de un grupo representa, ciertamente, la organización de sus acciones. Para conocer y comprender la vida de un grupo es necesario determinar su mundo de objetos, y esta determinación debe hacerse en función de los significados que aquellos poseen para los miembros del grupo. (Blumer, 1982, p. 51)

La construcción humana de un mundo intersubjetivamente significativo ${ }^{3}$ está en la

3 "Es intersubjetivo porque vivimos en él como hombres entre otros hombres, con quienes nos vinculan influencias y labores comunes, comprendiendo a los demás y siendo comprendidos por ellos. Es un mundo de cultura porque, desde el principio, el mundo de la vida cotidiana es un universo de significación para nosotros, vale decir, una textura de sentido que debemos interpretar para orientarnos y conducirnos en él. Pero esta textura de sentido -he aquí lo que diferencia el ámbito de la cultura del ámbito de la naturaleza- se origina en acciones humanas y ha sido instituido por ellas, por las nuestras y las de nuestros semejantes, contemporáneos y predecesores. Todos los objetos culturales -herramientas, símbolos, sistemas de lenguaje, obras de arte, instituciones sociales, etc.- señalan en su mismo origen y significado las actividades de sujetos humanos" (Schutz , 1974). Es necesario además hacer mención de que la idea de mundo intersubjetivamente construido parte del supuesto de la intercambiabilidad y reciprocidad de perspectivas, vale decir, de que "los objetos y sucesos de la experiencia humana están intersubjetivamente disponibles y son más o menos los mismos para todos los perceptores 'normales'", 
base de aquello que Schütz denominó conocimiento de sentido común. Así, Schütz señala que todo nuestro conocimiento del mundo:

[...] supone construcciones, es decir conjuntos de abstracciones, generalizaciones, formalizaciones e idealizaciones propias del nivel respectivo de organización del pensamiento. En términos estrictos, los hechos puros y simples no existen. [...] El mundo social no es esencialmente inestructurado. Tiene un sentido particular y una estructura de significatividades para los seres humanos que viven, piensan y actúan dentro de él. Los objetos de pensamiento construidos por los expertos en ciencias sociales se refieren a los objetos de pensamiento construidos por el pensamiento de sentido común del hombre que vive su vida cotidiana entre sus semejantes, y se basan en estos objetos. Las construcciones del especialista en ciencias sociales son, pues, construcciones de segundo grado, o sea, construcciones de las construcciones hechas por los actores de la sociedad misma [...]. (Schütz, 1974, p.37)

Con estos esbozos teóricos pretendemos simplemente hacer una introducción amplia y muy general a la perspectiva teórica que nos proporcionará las categorías, los conceptos y la estrategia de abordaje a partir de la cual intentaremos reconstruir algunas de las características del mundo intersubjetivamente significativo para los actores sociales que en la novela que será objeto de nuestro análisis juegan al drama de la vida. A esta tarea dedicaremos el resto del artículo.

\section{La vida de Lazarillo de Tormes Una lectura desde la teoría social}

El primero de los amos para los cuales Lázaro entra a servir como criado es un ciego dueño de una astucia singular, que se gana la vida desarrollando prácticas vinculadas a lo que vulgarmente podríamos denominar como "curanderismo". El niño admira la capacidad del ciego para recordar de memoria diferentes plegarias e invocaciones divinas aplicables a la cura de los más diversos males, y cómo la puesta en juego de esta capacidad le permite obtener limosnas más que suficientes para prodigarse el sustento diario sin inconvenientes.

Y fue ansi, que después de Dios, éste me dio la vida, y siendo ciego me alumbró y adestró en la carrera de vivir. Huelgo de contar a V. M. éstas niñerías para mostrar cuanta virtud sea saber los hombres subir siendo bajos, $\mathrm{y}$ dejarse bajar siendo altos, cuánto vicio. Pues tornando al bueno de mi ciego y contando sus cosas, V. M. sepa que desde que Dios crió el mundo, ninguno formó más astuto ni sagaz. En su oficio era un águila; ciento y tantas oraciones sabía de coro: un tono bajo, reposado y muy sonable que hacía resonar la

así como también -y muy especialmente- del encuentro con los demás, experimentado como simultaneidad vivida. "Esta simultaneidad es la esencia de la intersubjetividad, pues significa que capto la subjetividad del alterego al mismo tiempo que vivo en mi propio flujo de conciencia. En estos términos, se puede definir al alterego como 'el flujo subjetivo de pensamiento que puede ser experimentado en su presente vivido'. Y esta captación en simultaneidad del otro, así como su captación recíproca de mí, hacen posible nuestro ser en el mundo". (Natanson, 1974, pp. 20-21). 
iglesia donde rezaba, un rostro humilde y devoto que con muy buen continente ponía cuando rezaba, sin hacer gestos ni visajes con boca ni ojos, como otros suelen hacer. Allende desto, tenía otras mil formas y maneras para sacar el dinero. Decía saber oraciones para muchos y diversos efectos: para mujeres que no parían, para las que estaban de parto, para las que eran malcasadas, que sus maridos las quisiesen bien; echaba pronósticos a las preñadas, si traía hijo o hija. Pues en caso de medicina, decía que Galeno no supo la mitad que él para muela, desmayos, males de madre.

Pocos conocen la cultura, pero todos la reconocen. A la distancia que media entre conocimiento y reconocimiento, Bourdieu lo denomina "principio de buena voluntad cultural" (Bourdieu, 2006, pp. 321-322). El ciego es un lumpen mendicante, un habitante de los márgenes sociales, que sin embargo sabe bien que apropiarse eficazmente de ciertos recursos simbólicos propios de la cultura legítima -cultura en la España del siglo XVI que ve al mundo con ojos fuertemente religiosos- le permite llevar adelante prácticas sociales para las que siempre encuentra mercado. Recitando conjuros y ofreciendo curas para males diversos el ciego se asegura su sustento ${ }^{4}$. Lo que tal vez le resulte más asombroso a Lázaro es como el ingenioso ciego aún portando un doble estigma ${ }^{5}$, su carácter de ciego y su carácter de pobre, es capaz de poner en juego tácticas. Lo que resulta admirable a los ojos del niño es el ingenio del ciego para hacer nada menos que una "gestión exitosa de sus estigmas" (Goffman, 1989).

Nos parece pertinente vincular la idea goffmaniana de gestión del estigma con las consideraciones que Michel de Certeau hace respecto de cómo los sectores populares se valen de tácticas -y no de estrategias, porque las estrategias son las reglas del juego que impone el orden social legítimo, que es cosa de dominadores y no de dominados- para hacer frente a una cultura que los condena a la subalternidad:

Una distinción entre estrategias y tácticas parece presentar un esquema inicial más adecuado. Llamo estrategia al cálculo (o a la manipulación) de las relaciones de fuerzas que se hace posible desde que un sujeto de voluntad y de poder (una empresa, un ejército, una ciudad, una institución científica) resulta aislable. La estrategia postula un lugar susceptible de ser circunscrito como algo propio y de ser la base donde administrar las relaciones con una exterioridad de metas o de amenazas.

[...] En relación con las estrategias (cuyas figuras sucesivas desplazan este esquema demasiado formal y del cual el vínculo con una configuración histórica particular de la racionalidad estaría por precisarse), llamo táctica a la acción calculada que determina la ausencia de un lugar propio. Por tanto ninguna delimitación de la exterioridad le proporciona una condición de autonomía. La táctica no tiene más lugar que el del otro. Además, debe actuar con el te-

\footnotetext{
4 Ese acervo de conocimientos religiosos que el ciego se ha dado maña para ir adquiriendo de manera autodidacta a lo largo de su vida constituye su "tesoro". Siendo un lumpen, los retazos de la cultura legítima a partir de los cuales el ciego desarrolla sus tácticas no pueden ser sino adquiridos. Bourdieu señala que mientras que los dominantes nacen en la cultura legítima, los sectores subalternos la incorporan diferencialmente -de acuerdo a sus posibilidades- para poder conciliar más o menos efectivamente sus propias expectativas con las expectativas del orden social legítimo. (Bourdieu, pp. 334-335)
}

5 Goffman entiende por estigma a un "atributo fuertemente desacreditador" (Goffman, 1989, p. 13). 
rreno que le impone y organiza la ley de una fuerza extraña. [...] No cuenta pues con la posibilidad de darse un proyecto global ni de totalizar al adversario en un espacio distinto, visible y capaz de hacerse objetivo. Obra poco a poco. Aprovecha las "ocasiones" y depende de ellas, sin base donde acumular los beneficios, aumentar lo propio y prever las salidas. No guarda lo que gana. Este no lugar le permite, sin duda, la movilidad, pero con una docilidad respecto a los azares del tiempo, para tomar al vuelo las posibilidades que ofrece el instante. Necesita utilizar, vigilante, las fallas que las coyunturas particulares abren en la vigilancia del poder propietario. Caza furtivamente. Crea sorpresas. Le resulta posible estar allí donde no se le espera. Es astuta. En suma, la táctica es un arte del débil. (de Certeau, 2000, pp. 86-87)

De Certeau descree de una cultura dominante que impone sus preceptos a los dominados sin que estos opongan resistencia, y de unos dominados que se conformen con estar situados culturalmente hablando en los intersticios que le deja la cultura dominante. Sí afirma, en cambio, que las reglas de juego -las estrategias- las imponen los dominantes. Los dominados apelan a prácticas de desvío -tácticas- para hacer frente a esta dominación. Las tácticas son propias de los débiles (el arte de los débiles), las estrategias sólo de los dominantes.

El arte del ciego pasa por su capacidad para diferenciarse de la rusticidad y vulgaridad de los sectores populares, desarrollando una verdadera maestría en su oficio que dejaba conformes a aquellos que solicitaban sus servicios, y que lo distinguían de otros tantos ciegos que se prodigaban el sustento apelando a tácticas similares (era frecuente entre los no videntes de la época especializarse en recitar oraciones capaces de alejar ciertos males). La pericia del ciego a la hora de actuar en el teatro de la vida social incluía, como en todo actor que sabe jugar bien el papel que desempeña, un manejo de la materia corporal y gestual adecuado a las expectativas de los otros. No casualmente Lázaro recuerda que:

[...] en su oficio era un águila; ciento y tantas oraciones sabía de coro: un tono bajo, reposado y muy sonable que hacía resonar la iglesia donde rezaba, un rostro humilde y devoto que con muy buen continente ponía cuando rezaba, sin hacer gestos ni visajes con boca ni ojos, como otros suelen hacer.

Lo que el ciego implementa, entonces, son un conjunto de tácticas a partir de las cuales moviliza toda una dotación de recursos expresivos y simbólicos por medio de los cuales busca aquello que busca un buen actor goffmaniano. Esto es:

[...] definir a favor suyo toda situación social que lo tenga involucrado, por eso si existe algo que caracterice su modus operandi es poner en acto su capacidad de "impresionar" a los auditorios, en el sentido de persuadirlos de que aquello que él representa mediante su actuación representa lo que en realidad es. A partir de entonces, el actor se compromete implícitamente ante el auditorio y ante sí mismo de no parecer (al menos mientras duren esas interacciones) algo distinto de aquello que alega ser [...]. Cada vez que actúa, el sujeto debe movilizar una dotación suficiente de signos expresivos (o mantener una "fachada") para que los observadores no duden de lo que 
pudieran inferir a partir de las primeras apariencias. (Meccia, 2005, p. 3)

Después de pasar por manos del ciego y de un clérigo, Lázaro se topa con un noble venido a menos al cual entra a servir. El personaje en cuestión es un hidalgo que de nobleza sólo tiene el título, ya que materialmente es tanto o más pobre que el propio criado. La condición social del escudero en cuestión le impide rebajarse a trabajos de índole manual (no hablemos ya de mendigar), motivo por el cual para poder mantener incólume su fachada de hidalguía debe pasar por todo tipo de privaciones.

Lázaro relata su encuentro fortuito con el escudero afirmando que:

Andando así discurriendo de puerta en puerta, con harto poco remedio, porque ya la caridad se subió al cielo, topóme Dios con un escudero que iba por la calle con razonable vestido, bien peinado, su paso y compás en orden. Miróme, y yo a él, y díjome: "Mochacho, ¿buscas amo?" Yo le dije: "Sí, senor." "Pues vente tras mí -me respondió- que Dios te ha hecho merced en topar comigo. Alguna buena oración rezaste hoy." Y súbese por la calle arriba con tan gentil semblante y continente, que quien no le conociera pensara ser muy cercano pariente al conde de Arcos, o a lo menos camarero que le daba de vestir. ¿Quién encontrará a aquel mi señor que no piense, según el contento de sí lleva, haber anoche bien cenado y dormido en buena cama, y aun agora es de mañana, no le cuenten por muy bien almorzado?!

$\mathrm{Ni}$ bien se ven por primera vez, tanto niño como noble saben -o mejor, creen saber $^{6}$ - con una sola mirada quien es aquel que tienen en frente, cual es su posición social, qué papel juega cada uno en el teatro de la vida cotidiana. En relación a todo el conocimiento que se manifiesta incluso en las interacciones sociales más fortuitas, nos parece interesante señalar con Goffman que:

[...] la sociedad establece los medios para categorizar a las personas y el complemento de atributos que se perciben como corrientes y naturales en los miembros de cada una de esas categorías. El medio social establece las categorías de personas que en él se pueden encontrar. El intercambio social rutinario en medios preestablecidos nos permite trabajar con 'otros' previstos sin necesidad de dedicarles una atención o reflexión especial. Por consiguiente, es probable que al encontrarnos frente a un extraño las primeras apariencias nos permitan prever en qué categoría se

\footnotetext{
6 Entendemos que el conocimiento que está en la base de la lectura que el sujeto hace de los objetos sociales, de sus contextos y, sobre todo, de los otros, que es el que hace posible la interacción, tiene bastante de lo que Peirce llamó conocimiento por abducción. Goffman señala: "Es también muy importante que comprendamos que en realidad no conducimos nuestras vidas, tomamos nuestras decisiones y alcanzamos nuestras metas en la vida diaria en forma estadística o científica. Vivimos por inferencia. Yo soy, digamos, huésped suyo. Usted no sabe, no puede determinar científicamente que no he de robarle su dinero o sus cucharas. Pero por inferencia yo no lo he de hacer, y por inferencia usted me tendrá como huésped" (Goffman, 1974, p. 15). Peirce, por su parte, afirma: "Una abducción es un método para formar una predicción general sin ninguna verdadera seguridad de que tendrá éxito, sea en un caso especial o con carácter general, teniendo como justificación que es la única esperanza posible de regular nuestra conducta futura racionalmente, y que la inducción, partiendo de experiencias pasadas, nos alienta fuertemente a esperar que tenga éxito en el futuro" (Peirce, 1974, pp. 40-41). Y agrega que "la Ideoscopía es la descripción y clasificación de las ideas que pertenecen a la experiencia ordinaria o que surgen naturalmente en conexión con la vida cotidiana, sin tener en cuenta su grado de validez, ni sus aspectos psicológicos" (Peirce, 1974, p. 79).
} 
halla y cuáles son sus atributos [...]. Apoyándonos en estas anticipaciones, las transformamos en expectativas normativas, en demandas rigurosamente presentadas. (Goffman, 1974, p. 12)

Del fragmento de Goffman citado pueden extraerse al menos dos implícitos importantes. Primero, que solamente es posible establecer a priori tipologías humanas diversas -algunas prestigiosas/deseables, normales las más, desacreditadas algunas otras- en intercambios sociales rutinarios a partir de la aceptación naturalizada por parte de los actores de un orden social legítimo. Y segundo, que esos intercambios sociales rutinarios dicen muchísimo del orden social en el que se inscriben. Partiendo de supuestos como los enunciados, y poniendo en juego una estrategia microsociológica de indagación de lo social autores como Schütz, Blumer, Mead y Goffman, entre otros, reivindicarán el mundo de la vida, el mundo cotidiano, el mundo propio del "conocimiento de sentido común", como un objeto no solamente legítimo sino necesario para la producción de conocimiento sociológico.

En el caso de la relación que Lázaro entabla con el escudero empobrecido, la pobreza es un estigma que tanto amo como criado comparten, pero los papeles sociales muy diferenciales que cada uno desempeña los lleva a valerse de tácticas muy distintas frente al estigma. Lázaro es explícitamente un pobre, un huérfano mendigo, ese es el papel que juega en el teatro de la vida. En su caso, nada hay para encubrir respecto de una miseria que es evidente por donde se la mire. El escudero es un pobre implícito, que en la dramaturgia de su cotidianeidad recrea a diario el papel de un noble, de un dominante que trata por todos los medios posibles de encubrir su situación real para no verse desacreditado. El hidalgo empobrecido se ve compelido a ser todo lo discreto que pueda y a manejar eficazmente la enorme tensión que genera para un hombre de su condición social el estigma de la miseria material más absoluta (no tiene ni siquiera para comer). De su capacidad para poder cumplir eficazmente el papel que su máscara pública ${ }^{7}$ representa en el teatro de la vida social depende que el escudero, desacreditable en potencia por portación de miseria, no se convierta en desacreditado en acto. Goffman señala en este sentido que "aprender a encubrirse constituye una de las fases de la socialización de la persona estigmatizada y un momento decisivo de su carrera moral".

Dice Lázaro, respecto de los recursos escénicos que el escudero desplegaba en el teatro de la vida para sostener la fachada de nobleza y encubrir su condición de sujeto desacreditable:

Grandes secretos son, Señor, los que vos hacéis y las gentes ignoran! ¿A quién no engańará aquella buena disposición y razonable capa y sayo y quien pensará que aquel gentil hombre se pasó ayer todo el día sin comer, con aquel mendrugo de pan que su criado Lázaro trujo un día y una noche en el arca de su seno, do no se le podía pegar mucha limpieza, y hoy, laván-

\footnotetext{
7 Goffman entiende por "fachada personal" un conjunto de signos que revelan atributos del actor y que forman parte fundamental de su dotación expresiva. Como parte de esa fachada podemos incluir "las insignias del cargo a rango, el vestido, el sexo, la edad y las características raciales, el tamaño y el aspecto, el porte, las pautas de lenguaje, las expresiones faciales, los gestos corporales y otras características semejantes". (Gofmann, 1974, p. 35) Quizás el elemento más importante de la dotación de signos asociada con la clase social consista en los símbolos de status, mediante los cuales se expresa la riqueza material" (Gofmann, 1974, p. 48). "Ser un tipo dado de persona no significa simplemente poseer los atributos requeridos, sino también mantener las normas de conducta y apariencia que atribuye el grupo social al que se pertenece. (...) Un status, una posición, un lugar social no es algo material para ser poseído y luego exhibido; es una pauta de conducta apropiada, coherente, embellecida y bien articulada. Realizada con facilidad o torpeza, conciencia o no, engaño o buena fe, es sin embargo algo que debe ser representado y retratado, algo que debe ser llevado a efecto" (Gofmann, 1974, p. 86).
} 
dose las manos y cara, a falta de paño de manos, se hacia servir de la halda del sayo? Nadie por cierto lo sospechara. !Oh Señor, y cuántos de aquestos debéis vos tener por el mundo derramados, que padecen por la negra que llaman honra lo que por vos no sufrirían! Y agrega:

No sé yo cómo o dónde andaba y qué comía. ! Y velle venir a mediodía la calle abajo con estirado cuerpo, más largo que galgo de buena casta! Y por lo que toca a su negra que dicen honra, tomaba una paja de las que aun asaz no había encasa, y salía a la puerta escarbando los dientes que nada entre sí tenían.

La capa y el sayo, la limpieza, el buen peinado, la gallardía en el andar son indudablemente signos de distinción social, de estatus. Y el detalle de la paja entre los dientes es un signo de haber comido bien, de tener qué escarbar entre ellos, es un indicador de abundancia, de prodigalidad en el comer y en el vivir. Resulta evidente el esfuerzo que hace el escudero por cuidar minuciosamente cada detalle que pudiera dejarlo expuesto frente a la mirada de los otros, a los cuales busca infundir la creencia de que se hallan frente a un dominante y no frente a un lumpen de sangre azul. El hidalgo sabe bien que la creencia

[...] se fomenta mediante el ejercicio de la ascesis, es decir: el ejercicio consistente en dotarse de una armadura simbólica, de un quantum suficiente de signos que indiquen estatus. ¿Cómo acumular signos? Trabajando como un buen asceta sobre el cuerpo (vigilándolo) y sobre la lengua (para que no se suelte). El cuerpo y la lengua pueden llevar tanto a la comunión con el orden social como al ostracismo: todo dependerá de que se sepa convertirlos en depósitos inteligentes de los signos que delatan que se es "buen ciudadano". (Meccia, 2005, p. 4)

Hay otro episodio de la relación entre Lázaro y el escudero sobre el cual nos parece muy significativo detenernos. Lo reproducimos a continuación:

Desque vi ser las dos y no venía y la hambre me aquejaba, cierro mi puerta y pongo la llave do mandó, y tornóme a mi menester. Con baja y enferma voz e inclinadas mis manos en los senos, puesto Dios ante mis ojos y la lengua en su nombre, comienzo a pedir pan por las puertas y casas mas grandes que me parecía. Mas como yo este oficio le hobiese mamado en la leche, quiero decir que con el gran maestro el ciego lo aprendí, tan suficiente discípulo salí que, aunque en este pueblo no había caridad ni el año fuese muy abundante, tan buena maña me di que, antes que el reloj diese las cuatro, ya yo tenía otras tantas libras de pan ensiladas en el cuerpo y más de otras dos en las mangas y senos. Volvime a la posada y al pasar por la tripería pedí a una de aquellas mujeres, y diome un pedazo de una de vaca con otras pocas de tripas cocidas. Cuando llegue a casa, ya el bueno de mi amo estaba en ella, doblada su capa y puesta en el poyo, y él paseándose por el patio. Como entro, vínose para mí. Pensé que me quería reñir la tardanza, mas mejor lo hizo Dios. Preguntóme do venía. Yo le dije: "Señor, hasta que dio las dos estuve aquí, y de que vi que V.M. no venía, fuime por esa ciudad a encomendarme a las buenas gentes, $y$ hanme dado esto que 
veis". Mostréle el pan y las tripas que en un cabo de la halda traía, a lo cual el mostró buen semblante y dijo: "Pues esperado te he a comer, y de que vi que no veniste, comí. Mas tu haces como hombre de bien en eso, que mas vale pedillo por Dios que no hurtallo, y ansí Él me ayude como ello me parece bien. Y solamente te encomiendo no sepan que vives comigo, por lo que toca a mi honra, aunque bien creo que será secreto según lo poco que en este pueblo soy conocido [...].

Sentéme al cabo del poyo y, porque no me tuviese por glotón, calle la merienda; y comienzo a cenar y morder en mis tripas y pan, y disimuladamente miraba al desventurado señor mío, que no partía sus ojos de mis faldas, que aquella sazón servían de plato. Tanta lástima haya Dios de mí como yo había del, porque sentí lo que sentía, y muchas veces había por ello pasado y pasaba cada día. Pensaba si sería bien comedirme a convidalle; mas por me haber dicho que había comido, temía me no aceptaría el convite. Finalmente, yo deseaba aquel pecador ayudase a su trabajo del mío, y se desayunase como el día antes hizo, pues había mejor aparejo, por ser mejor la vianda y menos mi hambre. Quiso Dios cumplir mi deseo, y aun pienso que el suyo, porque, como comencé a comer y él se andaba paseando llegóse a mi y díjome: "Dígote, Lázaro, que tienes en comer la mejor gracia que en mi vida vi a hombre, y que nadie te lo verá hacer que no le pongas gana aunque no la tenga.". "La muy buena que tú tienes -dije yo entre mí- te hace parecer la mía hermosa." Con todo, parecióme ayudarle, pues se ayudaba y me abría camino para ello, y dijele:

- "Señor, el buen aparejo hace buen artífice. Este pan está sabrosísimo y esta uña de vaca tan bien cocida y sazonada, que no habrá a quien no convide con su sabor.".

- ¿Una de vaca es?”.

-“Sí, señor.".

-"Dígote que es el mejor bocado del mundo, que no hay faisán que ansí me sepa."

-"Pues pruebe, señor, y verá qué tal está."

Póngole en las uñas la otra y tres o cuatro raciones de pan de lo más blanco y asentóseme al lado, y comienza a comer como aquel que lo había gana, royendo cada huesecillo de aquellos mejor que un galgo suyo lo hiciera.

-"Con almodrote - decía - es este singular manjar."

- “Con mejor salsa lo comes tú", respondí yo paso.

-"Por Dios, que me ha sabido como si hoy no hobiera comido bocado."

-“'Ansí me vengan los buenos años como es ello!” -dije yo entre mí.

Pidióme el jarro del agua y díselo como lo había traído. Es señal que, pues no le faltaba el agua, que no le había a mi amo sobrado la comida. Bebimos, y muy contentos nos fuimos a dormir como la noche pasada. Contemplaba yo muchas veces mi desastre, que escapando de los amos ruines que había tenido y buscando mejoría, viniese a topar con quien no solo no me mantuviese, mas a quien yo había de mantener.

Goffman sostiene que el individuo es el conjunto de las diferentes máscaras que usa en las diferentes situaciones sociales en las que interactúa y papeles que desempeña. La 
máscara del escudero cambia según el otro que tenga delante (en el ámbito público, ante la mirada de los demás, es necesario mantener la impostura del hidalgo de buen vivir; en el detrás de escena $a^{9}$, cuando ese otro que mira es solamente Lázaro, la impostura continúa -el escudero continúa sosteniendo la ficción de haber comido- pero de una manera mucho más flexibilizada, ya que el hecho de que el niño sospeche que la condición de su amo no es la que aparenta, y que además lo vea comer con fruición no apareja descrédito social para el escudero ${ }^{10}$ ). A esta multiplicación de los sí mismos, a este desdoblamiento de un actor social, al hecho de que apele a diferentes máscaras que satisfagan a la vez la buena performance del papel que se juegue y, particularmente, las expectativas que el actor atribuye a quienes tenga delante, Goffman lo denomina "segregación de auditorios"11.

En el escudero la tensión es máxima porque tiene que cuidar una fachada muy alta con los escasísimos recursos materiales que posee, y porque el descubrimiento de su impostura implicaría la ruina de su yo personal y social. Lázaro, en el cual la fachada y la condición humilde son coincidentes, pareciera que por ello no tiene necesidad de desarrollar tácticas de encubrimiento. Sin embargo, el teatro de la vida social convierte a todos a su modo en impostores. Cuando el niño recién conoce a su nuevo amo -y todavía lo tiene en consideración por un sujeto materialmente opulento-, se presenta al escudero como un sujeto que no tiene mayores preocupaciones por el comer y el beber (cuando en realidad estaba desesperado por el hambre). Lázaro se pone la máscara del criado desinteresado y diligente, porque ve en la posibilidad de entrar a servir al escudero una oportunidad para mejorar su condición, para no pasar más privaciones. Y así como el niño ve en el hidalgo un buen partido, lo que pretende es que mediante su actuación el hidalgo vea en él al criado que está buscando, más preocupado por trabajar que por comer $^{12}$. El siguiente párrafo presenta en el libro la escena mencionada:

Estando así, díjome:

-“Tú, mozo, ¿̨has comido?”.

-"No, señor -dije yo-, que aun no eran dadas las ocho cuando con vuestra merced encontré."

-"Pues, aunque de mañana, yo había almorzado, y cuando ansí como algo, hágote saber que hasta la noche me estoy ansí. Por eso, pásate como pudieres, que después cenaremos.

9 "Hemos considerado dos tipos de regiones limitadas: las regiones anteriores, en las cuales se desarrollan puede llegar a desarrollarse una actuación particular, y las regiones posteriores, donde tiene lugar una acción que se relaciona con la representación, pero que es incompatible con las apariencias por ella suscitadas" (Goffman, 1974, p. 146).

$10 \mathrm{El}$ escudero es conciente de los peligros que conlleva su impostura y sabe que, "aunque de mala gana, los sujetos permitamos que ciertos símbolos de status establezcan el derecho de un actuante a un cierto tratamiento, siempre estamos listos a abalanzarnos sobre las fallas de la armadura simbólica, a fin de desacreditar sus pretensiones". Y que "cuando descubrimos que alguien con quien tratamos es un impostor y un fraude cabal, descubrimos que no tenía derecho a desempeñar el papel que desempeñó, que no era un beneficiario acreditado del status pertinente" (Goffman, 1974, p. 70)

11 "Merced a ella el sujeto se asegura de que aquellos ante quienes representa uno de sus papeles no sean los mismos individuos ante quienes representa un papel diferente en otro medio" (Goffman, 1974, p. 60)

12 Esta es una de las máscaras predilectas de los actores humildes de todos los tiempos, que al salir a buscar trabajo juegan frente al posible empleador la parodia de que la paga les interesa bastante menos que el hacer bien su trabajo. 
Y con todo, disimulando lo mejor que pude:

-"Señor, mozo soy que no me fatigo mucho por comer, bendito Dios. Deso me podré yo alabar entre todos mis iguales por de mejor garganta, y ansí fui yo loado della fasta hoy día de los amos que yo he tenido."

- "Virtud es esa -dijo él- y por eso te querré yo más, porque el hartar es de los puercos y el comer regladamente es de los hombres de bien."

- ¡ Bien te he entendido! -dije yo entre mí- ¡maldita tanta medicina y bondad como

aquestos mis amos que yo hallo hallan en la hambre!”

Finalmente, queremos decir unas palabras respecto de un fragmento que nos parece de una riqueza sociológica destacable. El escudero le cuenta a Lázaro cómo al encontrarse en su tierra con un oficial tuvieron una reyerta a causa de la manera en que este último le dirigió el saludo:

Acuérdome que un día deshonré en mi tierra a un oficial, y quise ponerle las manos, porque cada vez que le topaba me decía: ¡Mantenga Dios a vuestra merced!

-iVos, don villano ruin! -le dije yo-¿por qué no sois bien criado? ¿Manténgaos Dios, me habéis de decir, como si fuese quienquiera? De allí adelante, de aquí acullá, me quitaba el bonete y hablaba como debía.

- ¿Y no es buena manera de saludar un hombre a otro -dije yo- decirle que le mantenga Dios?"

-“¡Mira mucho de enhoramala! -dijo él-. A los hombres de poca arte dicen eso, mas a los mas altos, como yo, no les han de hablar menos de: ¡Beso las manos de vuestra merced!, o por lo menos:; Besoos, señor, las manos!, si el que me habla es caballero. Y ansí, de aquél de mi tierra que me atestaba de mantenimiento nunca más le quise sufrir, ni sufriría ni sufriré a hombre del mundo, del rey abajo, que ¡Mantengaos Dios! me diga.

-"Pecador de mí -dije yo-, por eso tiene tan poco cuidado de mantenerte, pues no sufres que nadie se lo ruegue."

El saludo -ya sea verbal, gestual, escrito o en cualesquiera de las combinaciones posibles de materias significantes pueda encontrárselo- es un género discursivo tan viejo como la comunicación humana. El saludo implica reconocimiento del otro y de su condición personal y social, por eso es común que sujetos se ofendan o se molesten fácilmente a causa de motivos que tienen que ver con la manera en que otros se dirigen (u omiten dirigirse) a ellos, y por eso también es frecuente que sujetos muy molestos con otros dejen de reconocerlos mediante la práctica de quitar el saludo (lo cual implica no reconocer al otro como un prójimo, quitarle entidad, reducirlo al papel de objeto inanimado). Goffman afirma:

La sociedad está organizada sobre el principio de que todo individuo que posee ciertas características sociales tiene el derecho moral a esperar que otros lo valoren y lo traten de un modo apropiado. En conexión con este principio hay un segundo, a saber: que un individuo que implícita o explícitamente pretende tener ciertas características sociales deberá ser en realidad lo que alega ser. En consecuencia, cuando un individuo proyecta una defini- 
ción de la situación y con ello hace una demanda implícita o explícita de ser una persona de determinado tipo, automáticamente presenta una exigencia moral a los otros, obligándolos a valorarlo y a tratarlo de la manera que tienen derecho a esperar las personas de su tipo. También, implícitamente, renuncia a toda demanda a ser lo que él no parece ser, y en consecuencia renuncia al tratamiento que sería apropiado para dichos individuos. Los otros descubren, entonces, que el individuo les ha informado acerca de lo que es y de lo que ellos deberían ver en ese es. (Goffman, 1974, p. 24)

El escudero al definirse y proyectarse ante los demás como un hidalgo, como un ser de alcurnia, como un distinguido social, define su situación y presenta la exigencia moral de ser tratado y valorado de la manera que tienen derecho a esperar las personas de su condición. Mientras que Lázaro ve en ese "que te mantenga Dios" una caritativa expresión de deseos por parte de aquellos con los que se topa, al hidalgo le parece una manera inadmisible de referirse a sujetos como él (y mucho más cuando entiende que aquellos que dirigen el saludo son inferiores sociales, como el oficial). Cuando el escudero le refiere a Lázaro el incidente aludido, le enseña también cómo espera que se dirijan a él diferentes sujetos sociales, cómo debería saludarlo un caballero noble, quien debería quitarse el bonete primero ante el otro, o cómo debería dirigirse a él una persona de condición humilde.

En los diferentes fragmentos de La vida de Lazarillo de Tormes que hemos reproducido y analizado se pone de manifiesto el enorme peso que tiene para los sujetos sociales que interactúan cotidianamente aquello que Alfred Schütz denominó "conocimiento de sentido común”. En un saludo, una conversación o cualquier interacción cotidiana por más nimia que parezca hay todo un ordenamiento social legítimo atravesando el conjunto de esas prácticas. Entendemos que los autores con cuyas categorías y marcos de referencia hemos trabajado en el presente artículo han tenido el mérito de haber advertido la enorme relevancia que tiene para la teoría social el posar la mirada sobre el mundo de la vida, el de bajar al llano de los actores que le ponen el cuerpo día a día al drama de la vida social, el de encarar la lectura de lo social a partir de las propias construcciones de los sujetos interactuantes, el de haber puesto de manifiesto que dejando de lado la concepción del investigador dios padre que mira a los actores sociales desde arriba otra teoría social es posible, no menos rigurosa, no menos cientifica que aquella que se pretende objetivista, pero sí de una gran riqueza teórica y de una enorme originalidad.

\section{Bibliografía}

- Anónimo (1967). La vida de Lazarillo de Tormes y de sus fortunas y adversidades. Buenos Aires: Kapelusz.

- Anónimo (1999). Poema del Cid. Barcelona: Losada

— Blumer, H. (1982). "La posición metodológica del interaccionismo simbólico" y "El análisis sociológico y la variable". En El interaccionismo simbólico: perspectiva y método. Madrid: Hora

- Bourdieu, P. (2006). "La buena voluntad cultural". En La distinción. Criterio y bases sociales del gusto. Barcelona: Taurus.

- De Certeau, M. (2000). "Valerse de: usos y prácticas". En La invención de lo 
cotidiano I. Artes de hacer. México D. F.: Universidad Iberoamericana, Instituto Tecnológico y de Estudios Superiores de Occidente.

- Goffman, E. (1974). La presentación de la persona en la vida cotidiana. Amorrortu, Buenos Aires.

- Goffman, E. (1989). Estigma. La identidad deteriorada. Amorrortu, Buenos Aires.

— Lanzuela Corella, María Luisa (2000). "La literatura como fuente histórica: Benito Pérez Galdós". En Actas del XIII Congreso de la Asociación Internacional de Hispanistas (pp. 259-266). Madrid: Castalia-Asociación Internacional de Hispanistas-Fundación Duques de Soria.

- Martini, S. y Halpern, G. (2000). "Imaginarios sociales". En Ford, A. y Martini, S. Cuadernos de Teoría del Periodismo 24 / El periodismo en la sociocultura contemporánea. Buenos Aires: CECSo.

- Meccia, E. (2005). "El teatro que no representa. Una reseña tardía con algunas reflexiones actuales de La presentación de la persona en la vida cotidiana de Erving Goffman”. Revista Argentina de Sociología, (4), pp. 161-168.

- Natanson, M. (1974). "Introducción”. En Schütz, A. El problema de la realidad social. Buenos Aires: Amorrortu.

- Peirce, Ch. (1974). La Ciencia de la Semiótica. Buenos Aires: Nueva Visión.

- Pińeiro, J. A. (2008). "Razón, modernidad, crisis". En Ciencia, medios, modernidad (Tesis de la carrera de Ciencias de la Comunicación). Buenos Aires: Facultad de Ciencias Sociales, Universidad de Buenos Aires.

- Quevedo, F. de (2007). Antología poética. Madrid: Espasa Calpe.

- Schütz, A. (1974). "El sentido común y la interpretación científica de la acción humana”. En El problema de la realidad social. Buenos Aires: Amorrortu. 